\title{
Optimal Choice of Cotton Subsidy Mode in China- Empirical Study Based on Principal Component Regression
}

\author{
Jianzhong Shi ${ }^{1}$, Yuhong $\mathbf{L i}^{2 *}$ \\ ${ }^{1}$ School of Environmental Engineering, Wuhan Textile University, Wuhan, China \\ ${ }^{2}$ Business School, Jinggangshan University, Ji'an, China \\ Email: shijianzhong@163.com, ${ }^{*}$ liyuhong0718@hotmail.com
}

Received May 22, 2013; revised June 22, 2013; accepted July 12, 2013

Copyright (C) 2013 Jianzhong Shi, Yuhong Li. This is an open access article distributed under the Creative Commons Attribution License, which permits unrestricted use, distribution, and reproduction in any medium, provided the original work is properly cited.

\begin{abstract}
Adopt principal component regression for researching the optimal subsidy mode of cotton production in China. The result indicates that, from the perspective of economic stimulatory effect, the optimal cotton subsidy in China is farm chemical subsidy rather than seed subsidy. The reason is that there are frequent pest disasters in cotton producing areas in China. So farm chemical subsidy is the most important factor ensuring cotton production. Meanwhile, cotton varieties must be optimized and improved to increase the ability to resist pests and diseases, and the forecasting for pests and diseases in cotton production areas must be enhanced, early warning mechanism and monitoring must be built, and in addition, it is strongly recommended that if financial resources allow, subsidies like seed subsidy, fertilizer subsidy, machinery subsidy and irrigation subsidy could also put into effect in China.
\end{abstract}

Keywords: China; Cotton Subsidy; Import; Principal Component Regression

\section{Introduction}

Since mankind entered the 21 st century, China's cotton import has been increasing yearly. In 2003, the total import was 870 thousand tons which was 5.1 times the total import in 2002; and in 2004, China imported 1.9 million tons of cotton, which was 11 times more than that in 2002, and in 2011, it reached 3.36 million tons, which was nearly 20 times that in 2002 .

The sharply increasing import of cotton was caused by the following reasons, for one thing, the hot export of textile products since joining WTO led to sharply increasing demand of cotton; for another thing, some developed countries, especially America, have been providing cotton industry and cotton export with subsidies which has made those countries have huge competitive advantages of costs, large amount of cotton import at low cost must attack Chinese cotton industry to some extent. Though developed countries like America promised to conceal the cotton export subsidy and reduce some other policies of supporting cotton subsidies, in fact, the subsidy promised to conceal is less than $10 \%$ of the concrete subsidies. In order to increase the growers' income and

${ }^{*}$ Corresponding author. to increase the added value of textile products and to change the growth mode of trade as well, it's promptly necessary to implement the policy of cotton subsidy, for cotton is a kind of strategic material that is as important as foodstuff.

But nowadays, the problem is that the policies of mechanical subsidy and chemical fertilizer subsidy of cotton production are still not put into effect except seed subsidy. Thus, are all the subsidies of input factors effective? And is the seed subsidy just the optimal subsidy mode?

This paper adopts principle component regression to calculate the different elasticity values of input factors in cotton acreage, unit output and production profit then find out the best choice of cotton subsidy modes from economic view, and for testing whether the nationwide general seed subsidy is the most reasonable.

OECD [1] (2006) analyzed the economic effects of each kind of subsidy policy though Policy Evaluation Model (PEM), the result indicates that the distorted effect of input subsidy on output. Rossi Schmitz [2] (2005) researched the input subsidy of American cotton production and its multi-economy effects correspondingly, it's suggested that irrigation subsidy can significantly reduce the cost of production. 
Jiao Wang and Haifeng Xiao [3] (2006) researched the concrete effects of different subsidy modes in increasing food outputs through an empirical plan model (PMP) in their article The Assessment of the Effect of Direct Subsidy Policies of Chinese Grains; Bo Chen (2005) [4] researched the effect by the comparison of providing growers with subsidies directly and increasing the input of science and technology in food production through Uzawa model; Zhiyi Cao and Tiejun Zhang [5] (2006) particularly researched the machinery operation and income of the growers who benefit from the subsidy of machinery purchasing and then built a relationship model of increasing the income of growers and the subsidy of purchasing. However, so far no scholars home and abroad have studied the problem of cotton subsidy choice in China.

\section{Model Selection and Data Processing}

\subsection{Basic Hypotheses}

To facilitate sorting out data, building modes and calculating, the following hypotheses are needed.

1) Assume that the combined effects generated by such elements as seeds selected, fertilizers, pesticides, machinery and irrigation equal to the sum total effect brought by separate elements. The unselected input elements are usually fixed or non-controllable, the function of which can be reflected through constant term in production function model.

2) Assume that the production flexibility of the input factors is fixed. Obviously, the production flexibility of various input elements annually is flexible during a long time. So these hypotheses may, to some extent, affect the accurate calculation of output flexibility of various production factors.

3) Assume that the impact of climate, natural disasters on citrus production is neglected. Actually, citrus production is influenced by natural conditions. Particularly, frozen disaster in some areas is fatal. Therefore, these hypotheses will influence the accurate calculation of element flexibility and technology advancement.

4) Neglect the change of institutions and policy.

5) Suppose, under WTO, the subsidy measure adopted by Chinese government mainly includes seed subsidy, fertilizer subsidy, farm chemical subsidy, machinery subsidy and irrigation subsidy.

\subsection{Model Selection}

To facilitate the calculation of flexibility value of cotton acreage, yield, and production profit by input elements, we choose C-D function.

$$
Y=\alpha X_{1}^{\beta_{1}} X_{2}^{\beta_{2}} X_{3}^{\beta_{3}} X_{4}^{\beta_{4}} X_{5}^{\beta_{5}}
$$

Where, $Y$ is the cotton-growing area (or unit yield or the production profits). $X_{1}, \cdots, X_{5}$ respectively refers to seed costs, fertilizer costs, pesticide costs, machinery costs and irrigation costs. $\beta_{1}, \cdots, \beta_{5}$ respectively refers to output elasticity coefficient of the input of seeds, fertilizers, pesticides, machinery and irrigation.

Being taken the logarithm on both sides of the function, the model can be transformed into the following:

$$
\begin{aligned}
\ln Y= & \ln \alpha+\beta_{1} \ln X_{1}+\beta_{2} \ln X_{2} \\
& +\beta_{3} \ln X_{3}+\beta_{4} \ln X_{4}+\beta_{5} \ln X_{5}
\end{aligned}
$$

\subsection{Data Processing}

To make research on the impacts of such elements as seed subsidies, fertilizer subsidies, subsidies for pesticides, machinery and irrigation subsidies on cotton production in China, we collected and sorted out the data, unit output of cotton in China during the time 1990-2011, labor profit unit area, as well as the seed costs per unit area, fertilizer costs, pesticide costs, machinery costs and irrigation costs (see Table 1).

It is noted that, cotton growers in China psychologically don't think labor cost at home is part of the total production cost. Thus, we define the labor profit as gross output minus total cost and plus the depreciation of family labor.

\subsection{Data Diagnosis}

Suppose

$$
\begin{aligned}
& y=\ln Y, z_{1}=\ln X_{1}, z_{2}=\ln X_{2}, \\
& z_{3}=\ln X_{3}, z_{4}=\ln X_{4}, z_{5}=\ln X_{5},
\end{aligned}
$$

then calculate the Correlation Coefficients of $z_{1}, z_{2}, z_{3}, z_{4}$, $z_{5}$ using software SAS (see Table 2), when $N=2$, Prob > $|r|$ under $\mathrm{H}_{0}:$ Rho $=0$.

The data in Table 2 indicate that the seed expenditure, chemical fertilizer expenditure, farm chemical expenditure, mechanical expenditure and irrigation expenditure of unit area are all significantly correlate with each other, which indicates that there exist multi-collinearity among the input factors.

The most common methods to solve multi-collinearity are principal component regression, ridge regression and least squares technique, while, principal component regression is used in this paper to solve such issue [6].

\section{Model Building and Data Analysis}

\subsection{Score of Principal Components}

When writing the data of variables $z_{1}-z_{5}$ during 19902011 as an $18 \times 5$ matrix, and standardizing the vectors, we could get a standard matrix and then calculate the coefficient matrix of vectors $R=\left[r_{i j}\right] 5 \times 5$, where, $r_{i j}$ is 
Tabel 1. Unit output, labor profit and input elements in China (1990-2011).

\begin{tabular}{|c|c|c|c|c|c|c|c|}
\hline year & Unit Output kg/h & Labor Profit Y/h & Seed Fee Y/h & Fertilizer Fee Y/h & Farm Chemical fee $\mathrm{Y} / \mathrm{h}$ & Machinery Fee Y/h & Irrigation Fee $\mathrm{Y} / \mathrm{h}$ \\
\hline 1990 & 1017.0 & 6025.95 & 106.05 & 495.15 & 305.1 & 45.9 & 56.1 \\
\hline 1991 & 1036.5 & 5720.85 & 113.55 & 561.45 & 343.8 & 68.55 & 93.3 \\
\hline 1992 & 792.0 & 3040.35 & 104.55 & 584.85 & 414 & 73.2 & 104.55 \\
\hline 1993 & 861.0 & 4493.25 & 132.75 & 658.35 & 453.75 & 82.95 & 107.55 \\
\hline 1994 & 901.5 & 8546.1 & 174.3 & 904.05 & 625.05 & 114 & 152.1 \\
\hline 1995 & 922.5 & 10841.4 & 230.4 & 1248.75 & 834.45 & 143.85 & 176.4 \\
\hline 1996 & 916.5 & 10021.8 & 238.2 & 1361.55 & 720.75 & 165.15 & 194.25 \\
\hline 1997 & 976.5 & 10358.1 & 260.1 & 1337.4 & 727.65 & 201.9 & 291.75 \\
\hline 1998 & 1024.5 & 7534.65 & 270.6 & 1195.8 & 775.5 & 220.5 & 271.35 \\
\hline 1999 & 1003.5 & 3619.35 & 286.2 & 1171.8 & 610.95 & 195 & 284.55 \\
\hline 2000 & 1069.5 & 7443.6 & 282.9 & 1151.55 & 599.85 & 190.65 & 277.35 \\
\hline 2001 & 1168.5 & 5329.05 & 317.85 & 1105.8 & 553.8 & 211.05 & 290.1 \\
\hline 2002 & 1228.5 & 7839.15 & 319.65 & 1213.05 & 513.75 & 231.6 & 324.15 \\
\hline 2003 & 1023 & 11337.45 & 368.4 & 1274.1 & 567.45 & 239.85 & 331.8 \\
\hline 2004 & 1144.5 & 8142.15 & 466.2 & 1527.9 & 487.35 & 408 & 336.15 \\
\hline 2005 & 1122 & 10394.1 & 449.85 & 1703.25 & 555.15 & 402.3 & 358.8 \\
\hline 2006 & 1276.5 & 11016.3 & 537 & 1888.5 & 637.2 & 480.75 & 428.4 \\
\hline 2007 & 1233 & 12337.65 & 565.5 & 2009.85 & 715.65 & 562.05 & 456.9 \\
\hline 2008 & 1249.5 & 6712.05 & 601.2 & 2531.25 & 812.4 & 682.5 & 465.9 \\
\hline 2009 & 1263.6 & 12195 & 616.2 & 2192.7 & 813 & 679.35 & 550.65 \\
\hline 2010 & 1161.45 & 24177.75 & 669.15 & 2287.2 & 842.1 & 807.45 & 594.75 \\
\hline 2011 & 1260.3 & 14355.15 & 776.7 & 2720.1 & 976.5 & 1336.05 & 757.8 \\
\hline
\end{tabular}

Notation: original data come from cost-benefit information on the national compilation of agricultural products (1991-2012); Y/h means RMB Yuan per hectare.

Table 2. Pearson correlation coefficients.

\begin{tabular}{cccccc}
\hline variable & $X_{1}$ & $X_{2}$ & $X_{3}$ & $X_{4}$ & $X_{5}$ \\
\hline$X_{1}$ & 1.00000 & $0.96902(<0.0001)$ & $0.68672(0.0004)$ & $0.94017(<0.0001)$ & $0.97576(<0.0001)$ \\
$X_{2}$ & $0.96902(<0.0001)$ & 1.00000 & $0.79728(<0.0001)$ & $0.92192(<0.0001)$ & $0.94601(<0.0001)$ \\
$X_{3}$ & $0.68672(0.0004)$ & $0.79728(<0.0001)$ & 1.00000 & $0.70106(0.0003)$ & $0.73334(0.0001)$ \\
$X_{4}$ & $0.94017(<0.0001)$ & $0.92192(<0.0001)$ & $0.70106(0.0003)$ & 1.00000 & $0.95107(<0.0001)$ \\
$X_{5}$ & $0.97576(<0.0001)$ & $0.94601(<0.0001)$ & $0.73334(0.0001)$ & $0.95107(<0.0001)$ & 1.00000 \\
\hline
\end{tabular}

Notation: the numbers in the brackets are the significance probabilities of the correlation coefficients, esp. it implies that it is significantly correlate when it is less than 0.05 .

the coefficient of index $i$ and index $j$ (where $i, j=1, \cdots, 5$ ), and then further calculate the eigenvalue $\lambda_{i}$ (where, $i=1$, $2, \cdots, 5$ ) (see Table 3).

According to the secular equation of $R\left|R-\lambda I_{5}\right|=0$, we can get the result using software SAS.

Five eigenvalues are indicated in Table 3, each of them corresponds with a principal component, and each principal component is a new variable. The contribution ratio of the first eigenvalue is $91.595 \%$, it indicates that the first principal component (Prin1) has reflected 91.595 of the whole information; likewise, Prin2 can reflect $10.71 \%$ of the whole information and so on.

Each principal component is a linear function of standardized variables $z_{1}-z_{5}$, when the yearly data of variables $z_{1}-z_{5}$ from 1990 to 2011 are substituted, the scores
Table 3. Eigenvalues of the correlation matrix.

\begin{tabular}{ccccc}
\hline Obs & Eigenvalue & Difference & Proportion & Cumulative \\
\hline 1 & 4.57944380 & 4.22834122 & 0.9159 & 0.9159 \\
2 & 0.35110258 & 0.30739402 & 0.0702 & 0.9861 \\
3 & 0.04370856 & 0.02569110 & 0.0087 & 0.9949 \\
4 & 0.01801747 & 0.01028988 & 0.0036 & 0.9985 \\
5 & 0.00772758 & & 0.0015 & 1.0000 \\
\hline
\end{tabular}

of all the principal components (Prin1 - Prin5) can be calculated.

\subsection{Principal Component Regressions}

In order to find out the C-D function of unit output, production profit respectively of the variables seed fee, fer- 
tilizer fee, farm chemical fee, machinery fee and irrigation fee, we must first find out the regression multicollinearity function of the logarithms $y$ of cotton acreage, unit output, production profit respectively of all the principal components Prin1 to Prin5. As the principal components are linear functions of principal components Prin1to Prin5, the regression function of $y$ the variables $z_{1}-z_{5}$. Using the REG module of software SAS as well as pcomit $=1,2,3,4$ outvif sentences to calculate, the result could be shown as Table 4 .

\subsection{Model Analysis}

1) Each of both the principal component functions of unit production and productive profit could retain a principal component, and $91.59 \%$ of the original information has been retained, which indicates that the final regression model is effective. According to the collinearity diagnosis, all the IPCVIF values are less than 0.5 , which indicates that final regression model has overcome the problem of multi-line.

2) In the regression model of unit output, the elasticity of seed expenditure, chemical fertilizers, farm chemical expenditure, mechanical expenditure or irrigation expenditure to the unit output is positive, which indicates that increment of the above five kinds of expenditure can help increase the unit output. Especially, increased input of farm chemical will make the unit increase significantly.

3 ) In the regression model of labor profit, the elasticity of farm chemical expenditure is the biggest, which also indicates that, in order to improve Chinese cotton growers' income, it's the most effective to increase farm che- mical expenditure.

\section{Conclusion and Recommendations}

\subsection{Basic Conclusion}

The above analysis has proved that increment of farm chemical expenditure will increase both unit output and labor profit. The major reasons are as follows [7]:

Firstly, in the growth period, cotton subjects to the harm by various pests. There are more than 300 kinds of pests in cotton field in China, among which 30 or more are major pests and more than 10 kinds of pests damage the cotton all year round. Due to the pests, there is $10 \%$ $15 \%$ loss average year, $30 \%$ loss in some serious years. In China pesticide usage takes a large proportion in comprehensively preventing diseases and pests. Annually, pesticide usage in cotton field takes $25 \%-30 \%$ in the total pesticide usage in China.

Secondly, the increment of farm chemical expenditure implies the dosage increase or the quality improvement of farm chemical. The serious problem of cotton production in China is the frequent plague of insects, and lower qualified varieties of cottons have weak ability to resist insect and disease disasters. According to our investigation and statistical analysis, in order to ensure their cotton output, the cotton growers will have to spray insecticide 5 to 8 times in the season of cotton growing, and in the year of pests and diseases, cotton growers will have to spay more times, nonetheless, the increment of farm chemical can lead to the increment of cotton output and cotton growers' income.

Table 4. Principal component regression coefficients and model test.

\begin{tabular}{|c|c|c|c|c|c|c|}
\hline \multirow{2}{*}{ Variable } & \multicolumn{3}{|c|}{ Unit products } & \multicolumn{3}{|c|}{ Labor profit } \\
\hline & Parameter Estimate & t Value & $\operatorname{Pr}>|t|$ & Parameter Estimate & t Value & $\operatorname{Pr}>|t|$ \\
\hline Intercept & 6.97117 & $457.75^{* *}$ & $<0.0001$ & 9.01705 & $117.37^{* *}$ & $<0.0001$ \\
\hline Prin 1 & 0.04689 & $6.44^{* *}$ & $<0.0001$ & 0.15413 & $4.19^{* *}$ & 0.0007 \\
\hline Prin2 & -0.11645 & $-4.43^{* *}$ & 0.0004 & 0.06007 & 0.45 & 0.6569 \\
\hline Prin 3 & -0.03670 & -0.49 & 0.6293 & -0.45996 & -1.22 & 0.2391 \\
\hline Prin 5 & 0.20903 & 1.18 & 0.2557 & 0.82456 & 0.92 & 0.3703 \\
\hline F value & \multicolumn{3}{|c|}{12.59} & \multicolumn{3}{|c|}{4.06} \\
\hline $\operatorname{Pr}>F$ & \multicolumn{3}{|c|}{$<0.0001$} & \multicolumn{3}{|c|}{0.014} \\
\hline $\mathrm{R}^{2}$ & \multicolumn{3}{|c|}{0.7973} & \multicolumn{3}{|c|}{0.5593} \\
\hline principal component regression & \multicolumn{3}{|c|}{$y=6.97117+0.04689 \operatorname{Prin} 1$} & \multicolumn{3}{|c|}{$y=9.01705+0.15413 \operatorname{Prin} 1$} \\
\hline Collineation diagnose & \multicolumn{3}{|c|}{$z_{1}(0.0455)$} & $z_{4}(0.04$ & \multicolumn{2}{|c|}{$z_{5}(0.045)$} \\
\hline
\end{tabular}

Notation: 1) Prin1 - Prin5 are cross-cut, removing one of them will not impact the regression coefficient of the other principal components in the regression function; 2) ${ }^{*}$ indicates significance under $0.05{ }^{* *}$ indicates significance under $0.01 ; 3$ ) In the brackets on the last line in collinearity diagnosis is IPCVI.F., although two of the principal component regressions of unit output are significant, the IPCVIF of the farm chemical expenditure is 2.29053 when two of the principal components are retained to do principal component regression, it's much bigger than 0.5 , which implies that the multicollinearity is still not eliminated, therefore, only one of the principal components could be retained to do linear principal component regression here; 4) the parameter estimates are the coefficients of principal components. 
Therefore, the optimal choice is farm chemical subsidy other than seed subsidy for economic view. Increasing farm chemical subsidy most effectively stimulates the increase of labor profit. Moreover, farm chemical subsidy can regulate the market and induce more growers to buy high-performance and low toxicity as well as ecofriendly organic pesticides with sufficient fund, so that the quality of cotton and the natural environment are protected.

In addition, besides farm chemical subsidy, other choices like seed subsidy, fertilizer subsidy, machinery subsidy and irrigation subsidy also play a positive role on cotton production in China.

\subsection{Recommendations}

According to the above analyses, following recommendations would be given to the government [8]:

Firstly, encourage the natural control to play role in pest prevention and build pest supervision and disaster warning mechanisms; bring the natural control factors such as spices of resisting diseases and pests, natural enemy, ecological adjustments forced by human into full play in restraining pests, meanwhile, widely use nonchemical control measures like biological farm chemical, radiation-sterile technique, chemical and physical trapping and killing to gradually reduce the dependence on chemicals (Jinjie Cui et al., 2007), and finally decline the use of farm chemicals. Of course, advanced preventive treatment will increase cotton growers' financial burden more or less.

Secondly, in China, special fund should be set to encourage the production of high-performance and low toxicity pesticide for scientific research institutes and enterprises. Strengthened efforts should be made to research pest prevention so as to make the high-tech plays a positive role.

Thirdly, genetic improvement and species optimization of cotton is encouraged so as to improve its capability of disease and pest resistance. And it's indispensable to strengthen the work of pest forecast and prevention and establish disease and pest supervision and early warning mechanism.

Finally, if the financial resource allows, it's necessary to combine subsidy of seed, fertilizer, farm chemical, machinery and irrigation. The proportion of the combination can depend on both state policy and cotton growers. But too scattered subsidy and low effects due to small number of separate subsidy should be avoided.

\section{Acknowledgements}

This paper is financially supported by the projects Young and Mid-Aged Scientific and Technical Innovation Team of Colleges and Universities in Hubei (ID: T201207) and Foreign Trade and Economic Development: Empirical Study on Southwest Minority Region of China (ID: JRB 11046).

\section{REFERENCES}

[1] OECD, "Decoupling Agricultural Support from Production," 2006. www.oecd.org/publications/Policy briefs

[2] F. Rossi, A. Schmitz and T. G. Schmitz, "The Multiplicative Effect of Water Subsidies and Price Support Payments: The Case of US Cotton," Journal of International Agricultural Trade and Development, Vol. 1, No. 1, 2005, pp. 55-70.

[3] J. Wang and H. F. Xiao, "The Assessment of the Effect of Direct Subsidy Policies of Chinese Grains," China Rural Economics, No. 12, 2006, pp. 4-12.

[4] B. Chen and Y. P. Wang, "Investigation and Analysis of the Reform of food Subsidy Modes in Hubei," Economic Issues, No. 3, 2006, pp. 50-52.

[5] Z. Y. Cao and T. J. Zhang, "The Analysis of the Effect of the Income of Growers and Machinery purchasing Subsidy," Study on Mechanize, No. 12, 2006, pp. 66-69.

[6] X. Y. Wang, D. J. Liu and C. J. Qi, "The Construction of Principal Component Regression Model of Vegetables Total Output in China and Its Prediction," Agricultural System Science and Synthetic Researches, Vol. 22, No. 2, 2006, pp. 132-138.

[7] J. J. Cui, et al., "Experience and Expectation of the Research on Synthetic Control of Cotton Pests," Journal of Cotton, No. 9, 2007, pp. 385-390.

[8] J. C. P. Yu, "An Optimal Pricing Policy for Reuse Products with Incentive Subsidy Demand," International Journal of Engineering and Industries, Vol. 4, No. 1, 2013, pp. 20-29. doi:10.4156/ijei.vol4.issue 1.3 